\title{
Evaluating the cost-effectiveness of diagnosing and treating phantom cows in seasonal-calving dairy herds
}

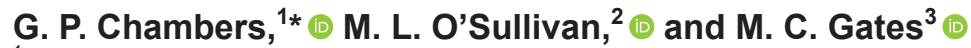 \\ ${ }^{1}$ Zoetis New Zealand Limited, Level 5, 8 Mahuhu Crescent, Auckland 1010, New Zealand \\ ${ }^{2}$ Veterinary Centre Limited, Oamaru, 311 Thames Street, Oamaru 9400, New Zealand \\ ${ }^{3}$ EpiCentre, School of Veterinary Science, Massey University, Private Bag 11 222, Palmerston North 4442, New Zealand
}

\section{ABSTRACT}

The objective of this study was to explore the costeffectiveness of using a progesterone-based synchrony program to manage phantom cows on seasonal-calving dairy farms. Phantom cows were defined as cows that had been artificially inseminated $\leq 14 \mathrm{~d}$ after mating start date (MSD), were not subsequently detected in estrus, and were diagnosed nonpregnant at a pregnancy diagnosis conducted approximately $49 \mathrm{~d}$ after MSD. Decision-tree analysis was applied to data from a previous randomized controlled trial in which phantom cows $(\mathrm{n}=378)$ from spring-calving dairy farms were randomly allocated to an untreated control group or were immediately treated with a 10-d progesteronebased synchrony program with fixed-time artificial insemination. The net economic return of treating all cows presented by the farmer for pregnancy diagnosis that were diagnosed nonpregnant was compared with no intervention. The net return was calculated per cow present at MSD because the decision trees followed all cows present at MSD through to mating end date to account for farmers inadvertently presenting ineligible cows for pregnancy diagnosis and possible treatment. Probabilities, costs, and benefits of reproductive outcomes were based on published data and expert opinion. The effects of key variables on the economic return were tested by sensitivity analysis. Phantom cow intervention delivered a net return of $\mathrm{NZ} \$ 4.451$ (at the time of the study, NZ\$1 = US\$0.6629) per cow present at MSD. The sensitivity of pregnancy diagnosis, the proportion of ineligible cows presented by the farmer for pregnancy diagnosis, and the prevalence of phantom cows were highly influential on the net economic return from phantom cow intervention. These findings suggest that treatment of phantom cows in seasonal-calving dairy farms using a progesterone-based synchrony pro-

Received July 29, 2019.

Accepted May 2, 2020.

*Corresponding author: gregory.chambers@zoetis.com gram is economically viable based on the current model assumptions. Accurate cow selection and pregnancy diagnosis are essential to success, and veterinarians and animal health advisors can improve the net economic return of intervention by selecting farms likely to have a higher prevalence of phantom cows based on the presence of observable risk factors.

Key words: phantom cows, dairy cattle, reproduction, economics, decision tree analysis

\section{INTRODUCTION}

Efficient pasture utilization in seasonal calving dairy herds is facilitated by having compact calving periods. In pastoral production systems such as in New Zealand, this is most often achieved by using intense periods of estrus detection and AI lasting 6 to 9 wk followed by a short period of natural mating with beef breed bulls to impregnate cows that failed to conceive to AI (Verkerk, 2003).

Phantom cows have been defined as cows that have been inseminated, not detected in estrus within at least $24 \mathrm{~d}$ of the insemination, and subsequently classified as having failed to become pregnant to the insemination (Cavalieri et al., 2003b). Phantom cows tend to conceive later in the season and have a greater risk of remaining nonpregnant at the end of the seasonal mating period than nonphantom cows (Cuttance and Mason, 2015), which can lead to significant economic losses from reduced lactation lengths in the following season due to delayed calving caused by delayed conception, lower value of calves sired by beef bulls compared with AIbred replacement calves, and higher risks of culling for nonpregnant cows. The prevalence of phantom cows in New Zealand dairy herds has recently been estimated at $9.1 \%$ among cows that were inseminated $\leq 21 \mathrm{~d}$ after the mating start date (MSD), did not return to estrus, and were presented for pregnancy diagnosis 35 to $42 \mathrm{~d}$ postinsemination (Cuttance and Mason, 2015).

Given the economic importance of phantom cows to the New Zealand dairy industry, interest is growing in 
exploring interventions to treat phantom cows that are identified through routine pregnancy diagnosis. In one previous study, administering $\mathrm{PGF}_{2 \alpha}$ to phantom cows with a corpus luteum $(\mathbf{C L})$ did not improve reproductive performance, whereas the use of a progesterone-based synchrony program for cows without a CL decreased the time to conception and increased the proportion of cows that were pregnant at the end of the seasonal mating period, but only in cows with ovarian follicles $<10 \mathrm{~mm}$ in diameter (Cuttance and Mason, 2015). In a second study, resynchronized phantom cows that had been treated with a progesterone-based synchrony program due to being not detected in estrus before MSD had greater odds of being pregnant on d 42 after MSD (Bates et al., 2016). The authors of the latter study suggested that prevention may be more cost-effective than treatment in this subgroup of cows, but neither study included an economic analysis of phantom cow intervention, nor appraised the blanket treatment of all phantom cows with a single protocol.

Managing phantom cows can be particularly challenging in New Zealand dairy herds because pregnancy diagnosis is often scheduled as a single veterinary visit at a time when pregnant cows are expected to be sufficiently far along in gestation that pregnancies can be reliably detected, which restricts intervention to cows mated early in the seasonal mating period to allow treatment to be completed before the mating end date. This introduces the risk that pregnant cows may be erroneously diagnosed as phantom cows because the diagnostic sensitivity of the operator is unlikely to be $100 \%$. In addition, farmers may inadvertently present cows that were mated and conceived after the period of interest due to errors in recording and cow selection, particularly if bulls were introduced to the cows and estrus was not detected. These pregnancies may not be detectable at the time of pregnancy diagnosis. Any phantom cow treatment programs that include $\mathrm{PGF}_{2 \alpha}$ or AI may terminate the pregnancies of any cows that were erroneously diagnosed as phantom cows (Sturman et al., 2000).

The cost-effectiveness of implementing a phantom cow intervention program for any given dairy herd is therefore likely to depend on complex factors including the true prevalence of phantom cows in the herd, the ability of farmers to accurately detect cows in estrus, AI conception rates, the accuracy of pregnancy diagnosis, and the assumed efficacy of treatment. However, to our knowledge, there has been no peer-reviewed economic analysis of phantom cow intervention to assist farmers and animal health advisors in making herd-level decisions. The results of analyses of resynchronization programs cannot be generalized to phantom cows because resynchronization programs are typically applied to cows whose reproductive cycles have already been synchronized. Phantom cows may have been inseminated to a spontaneous estrus or have undergone reproductive synchronization. Using decision-tree analysis, the objective of this study was to explore the cost-effectiveness of using a progesterone-based synchrony program to manage phantom cows in a typical spring-calving pastoral New Zealand dairy herd.

\section{MATERIALS AND METHODS}

\section{Decision Tree Structure}

A decision-tree framework was used to estimate the economic value of the treatment of phantom cows with a progesterone-based synchrony program against no treatment on a typical, seasonal-calving, commercial dairy farm in New Zealand. Decision trees are a widely used animal health economics framework that allow the net effect of intervention to be calculated when there are multiple possible outcomes due to chance events (Dijkhuizen et al., 1995), and therefore provide a structure for accounting for the chance events and their respective costs. This is particularly useful for accounting for the costs of nonphantom cows being treated as phantom cows, caused by errors in cow selection or pregnancy diagnosis. In a decision tree, chance events are represented in chronological order by nodes (points at which an individual subject must take one of at least 2 possible paths). Paths lead to terminal branches in the tree, which represent all the possible and mutually exclusive outcomes for an individual in the given scenario. The economic value of each outcome can be multiplied against the probability of the outcome occurring to generate an overall weighted value for the farm-level intervention.

Two decision trees were compared: one in which no phantom cow intervention was performed and one in which pregnancy diagnosis was performed on all cows presented by the farmer and nonpregnant cows were assumed to be phantom cows and immediately enrolled in the progesterone-based synchrony program. The 2 decision trees had identical structures but different node probabilities. The net value of intervention was calculated by subtracting the weighted value of the notreatment decision tree from the weighted value of the treatment decision tree. The decision trees were first constructed as a spreadsheet (Microsoft Corporation, Redmond, WA) and then programmed into R (R Core Team, 2017).

The decision-tree structure was informed by the design of a previously conducted randomized controlled trial in which veterinary-diagnosed phantom cows from 14 commercial dairy herds were randomly allocated to 
treatment with a progesterone-based synchrony program or no treatment (Chambers et al., 2020). Phantom cows were defined as cows that were artificially inseminated $\leq 14 \mathrm{~d}$ after MSD, were not subsequently detected in estrus, and were diagnosed nonpregnant at a pregnancy diagnosis conducted 35 to $49 \mathrm{~d}$ postinsemination. The study began at this pregnancy diagnosis, when phantom cows were randomly allocated to control and treatment groups. Cows allocated to the control group received no treatment and were mated naturally by bulls to spontaneous estrus. Cows in the treatment group were immediately enrolled in a 10-d progesteronebased synchrony program consisting of an injection of buserelin (GnRH agonist) and insertion of an intravaginal device containing progesterone, followed $7 \mathrm{~d}$ later by injections of dinoprost (synthetic $\mathrm{PGF}_{2 \alpha}$ ) and equine chorionic gonadotrophin and removal of the intravaginal device, followed $2 \mathrm{~d}$ later by injection of buserelin, and ending with fixed-time artificial insemination (FTAI) on the following day (Bryan et al., 2013). Cows in both the treatment and control group were mixed with bulls at the end of each farm's AI period, before the initial pregnancy diagnosis at enrolment and until the end of each farm's mating period, which occurred at a mean of $91(\mathrm{SD}=15.25) \mathrm{d}$ after MSD. Treatment group cows were separated from bulls on the day before FTAI and reintroduced after FTAI. Reproductive data were collected from the cows to determine the proportion of cows that were pregnant at the end of the seasonal mating period and the enrolment to conception interval of pregnant cows. The study methodology is described in full by Chambers et al. (2020), but a summary is provided in the Appendix.

The events included in the decision tree were based on the intent to identify and treat phantom cows that were inseminated in the first $14 \mathrm{~d}$ of the seasonal mating period, thereby allowing treatment to be completed within a $70-d$ seasonal mating period. Estrus detection by observation of disturbed tail paint (Macmillan and Curnow, 1977) was conducted by farm staff until at least d 49. On d 49, the farmer was instructed to present eligible cows to a veterinarian (i.e., all cows that were inseminated $\leq 14 \mathrm{~d}$ after MSD and that were not recorded as returning to estrus 15 to $49 \mathrm{~d}$ after MSD). Day 49 was chosen for diagnosis of phantom cows to ensure cows that remained pregnant to an insemination $\leq 14 \mathrm{~d}$ after MSD would have a gestational age $\geq 35 \mathrm{~d}$ at pregnancy diagnosis (the minimum gestational age detectable by pregnancy diagnosis was assumed to be $35 \mathrm{~d})$.

Because ineligible cows (i.e., all other cows aside from eligible cows) may be inadvertently presented by the farmer and diagnosed as phantom cows, the decision tree commenced at the MSD, not at enrolment of phantom cows on d 49 after MSD, to account for the probability of ineligible cows being presented and treated. The net return was therefore calculated per cow present at MSD.

The decision tree is presented here in 2 parts with the first part describing the paths a cow may follow between MSD and d 49 (Figure 1) and the rest of the decision tree describing the paths a cow may follow between $\mathrm{d}$ 49 and the end of the mating period (Figure 2). On d 49, the cows were categorized into one of 4 statuses based on whether they were inseminated during the period of interest and their true pregnancy status on $d$ 49. Eligible cows are marked with an asterisk (Figures 1 and 2). The parts shown in Figure 2 are replicated 9 times in the decision tree (one for each branch ending at d 49 of Figure 1) but only a single example is shown here. Each replicate has the same structure but different probabilities depending on cow status.

Status A Cows (Pregnant, Early Conception). These cows conceived $\leq 14 \mathrm{~d}$ after MSD and are $\geq 35 \mathrm{~d}$ pregnant on d 49, which reduces the risk of being falsely classified as nonpregnant on pregnancy examination. Status A cows were eligible for pregnancy diagnosis on d 49 (status $=\mathrm{A}^{*}$ ) unless they were re-inseminated between $\mathrm{d} 14$ and 49 after MSD (but the pregnancy was not terminated by AI, i.e., status $=\mathrm{A})$.

Status B Cows (Pregnant, Late Conception). These ineligible cows conceived 15 to $49 \mathrm{~d}$ after MSD and are $<35 \mathrm{~d}$ pregnant at the initial pregnancy diagnosis on d 49, which increases the risk of being falsely classified as nonpregnant on pregnancy examination. If these cows are erroneously presented by the farmer, they are assumed to be diagnosed nonpregnant aside from false-positive diagnoses and will be treated as phantom cows.

Status C Cows (Nonpregnant, True Phantom Cows). These cows were inseminated $\leq 14 \mathrm{~d}$ after MSD but did not conceive and were not re-inseminated between d 15 and 49 after MSD. They are nonpregnant on d 49 and eligible for pregnancy diagnosis.

Status D Cows (Nonpregnant and Not Eligible for Pregnancy Diagnosis). These cows are nonpregnant on d 49 but are ineligible for being presented by the farmer because either (1) they were not inseminated $\leq 14 \mathrm{~d}$ after MSD, but may have been subsequently unsuccessfully inseminated, or (2) they were inseminated $\leq 14 \mathrm{~d}$ after MSD and conceived but were subsequently re-inseminated and the insemination terminated the pregnancy, or did not conceive and were subsequently re-inseminated.

Nodes (oval shapes) represent the chance events of estrus detection and insemination, conception (or remaining pregnant if a pregnant cow was re-inseminated after conception), selection and presentation by the 
farmer on d 49 for pregnancy diagnosis, pregnancy diagnosis outcome, and whether the cow is pregnant at the end of the seasonal mating period. In the case of no intervention, the probability of both eligible and ineligible cows being presented for pregnancy diagnosis on d 49 was set to zero, and no cows proceeded to pregnancy diagnosis or treatment but their probability of being pregnant at the end of the seasonal mating period was still calculated. Terminal branches (arrowheads) represent final outcomes at mating end date. The probabilities assigned to each branch stemming from a node were based on the intervention study, published data, and national statistics (Table 1), with branch probabilities summing up to 1.00 within each node. Further details on the assumptions and economic values used for the decision tree are presented in the Appendix.

The nodes are described chronologically:

Node 1: Presented for $A I \leq 14 d$ After $M S D$ (Figure 1). This node was included to account for cows that were not inseminated $\leq 14 \mathrm{~d}$ after MSD and are therefore ineligible for phantom cow treatment but may be presented by the farmer erroneously.

Node 2: Conceived to AI (Figure 1). Cows that conceived $\leq 14 \mathrm{~d}$ after MSD are less likely to display estrus and be re-inseminated 15 to $49 \mathrm{~d}$ after MSD, and provided they are not re-inseminated, are expected to be presented by the farmer for phantom cow identification, making them subject to the accuracy of pregnancy diagnosis on d 49.

Node 3: Mated/Re-mated 15 to 49 d After MSD (Figure 1). Cows that were mated 15 to $49 \mathrm{~d}$ after MSD are ineligible for phantom cow intervention but may be presented by the farmer erroneously and are therefore accounted for in the decision tree. It was assumed that these cows may either be mated artificially or naturally by bulls. The probability of being mated or re-mated 15 to 49 d after MSD depended on whether the cow was presented for AI $\leq 14 \mathrm{~d}$ after MSD and conceived (node $3 \mathrm{a}$ ), did not conceive (node $3 \mathrm{~b}$ ), or was not presented $\leq 14 \mathrm{~d}$ after MSD (node $3 \mathrm{c}$ ).

Node 4: Remained Pregnant/Conceived to Mating (Figure 1). For cows that conceived to AI $\leq 14 \mathrm{~d}$ after MSD and were re-inseminated 15 to 49 d after MSD, this node accounted for the probability of remaining pregnant (node 4a). For all other cows, this node accounted for the probability of conceiving to AI 15 to 49 d after MSD, which was assumed to be the same for cows that were unsuccessfully inseminated $\leq 14 \mathrm{~d}$ after MSD and cows that were not inseminated



Figure 1. Simplified structure of events between mating start date (MSD) and initiation of phantom cow intervention in a decision-tree analysis of a phantom cow intervention program on a seasonal-calving dairy farm. Chance nodes are represented by ovals and events by branches. $\mathrm{d}=$ day in relation to MSD. $\mathrm{A}=\geq 35 \mathrm{~d}$ pregnant; $\mathrm{B}=<35 \mathrm{~d}$ pregnant; $\mathrm{C}=$ inseminated $\leq 14 \mathrm{~d}$ after MSD, not subsequently detected in estrus and nonpregnant (phantom cow); $\mathrm{D}=$ inseminated $\leq 14 \mathrm{~d}$ after MSD and conceived but subsequently re-inseminated and terminated pregnancy or failed to conceive but subsequently re-inseminated or not inseminated $\leq 14 \mathrm{~d}$ after $\mathrm{MSD} .{ }^{*}=$ eligible for identification and treatment of phantom cows. 
$\leq 14 \mathrm{~d}$ after MSD (nodes 4b and 4c). Accounting for conception to this mating in cows that did not conceive $\leq 14 \mathrm{~d}$ after MSD is necessary for estimating the probability of cows $<35 \mathrm{~d}$ pregnant being presented for pregnancy diagnosis. Cows are categorized into status $\mathrm{A}-\mathrm{D}$ at this node.

Node 5: Presented for Pregnancy Diagnosis (Figure 2). This node was added because errors in cow identification, record-keeping, or drafting of cows could result in the farmer omitting eligible cows (cows that were inseminated $\leq 14 \mathrm{~d}$ after MSD and that were not recorded as returning to estrus 15 to $49 \mathrm{~d}$ after MSD) or presenting ineligible cows (all other cows). The probability of being presented therefore depended on whether the cow was eligible $\left(\mathrm{A}^{*}\right.$ or $\mathrm{C}^{*}$; node $\left.5 \mathrm{a}\right)$ or ineligible (A, B, or D; node 5b).

Node 6: Diagnosed Pregnant (Figure 2). All cows diagnosed nonpregnant were categorized as phantom cows and immediately enrolled in a 10 -d progesteronebased synchrony program with FTAI. The sensitivity of pregnancy diagnosis determines the probability of status A cows being diagnosed as pregnant (true positives) and not enrolled (node 6a). The probability of status $\mathrm{B}$ cows (node $6 \mathrm{~b}$ ), and status $\mathrm{C}$ and $\mathrm{D}$ cows (node $6 \mathrm{c}$ ) being diagnosed pregnant (false positives: they were either nonpregnant or $<35 \mathrm{~d}$ pregnant) was assumed to be 1 - the specificity of pregnancy diagnosis, with the remainder diagnosed nonpregnant and assumed to be phantom cows. Cows not presented by the farmer for pregnancy diagnosis skip this node, and in the case of no intervention, all cows skip this node.

Node 7: Pregnant at Mating End Date (Figure 2). This node describes whether a cow is diagnosed pregnant at a final pregnancy diagnosis conducted at least $40 \mathrm{~d}$ after the end of the seasonal mating period. The probability of being pregnant depended on the cow's status at d 49 and whether she was treated or untreated (nodes 7a-h).

\section{Outcome Assumptions}

Status A Cows. These cows either were inseminated and conceived $\leq 14 \mathrm{~d}$ after MSD and not subsequently detected in estrus or were mated again before d 49 but the pregnancy was not terminated. We assumed that status A cows conceived $7 \mathrm{~d}$ after MSD (the midpoint between d 0 and d 14 after MSD) and 50\% carried an AI-bred heifer fetus, which was replaced by a non-AIbred fetus ("bobby calf") if the cow was treated and re-conceived. Status A cows that were treated and con-

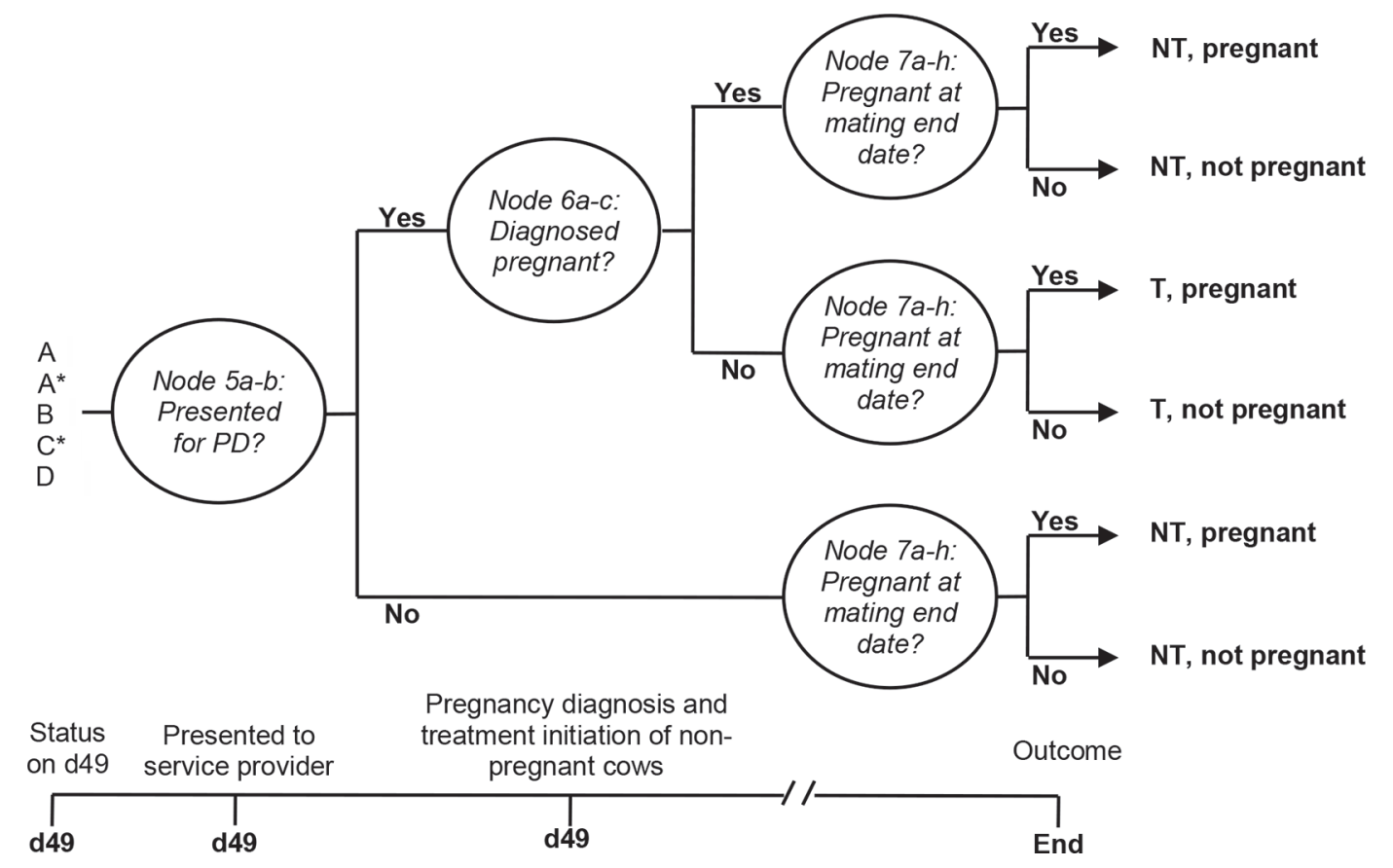

Figure 2. Simplified structure of events between initiation of phantom cow intervention and mating end date in a decision-tree analysis of a phantom cow intervention program on a seasonal-calving dairy farm. Chance nodes are represented by ovals and events by branches. A $=\geq 35 \mathrm{~d}$ pregnant; $\mathrm{B}=<35 \mathrm{~d}$ pregnant; $\mathrm{C}=$ inseminated $\leq 14 \mathrm{~d}$ after mating start date (MSD) and nonpregnant (phantom cow); $\mathrm{D}=$ inseminated $\leq 14$ $\mathrm{d}$ after MSD and conceived but subsequently re-inseminated and terminated pregnancy or failed to conceive but subsequently re-inseminated or not inseminated $\leq 14 \mathrm{~d}$ after MSD. $\mathrm{PD}=$ pregnancy diagnosis; $\mathrm{d}=$ day in relation to mating start date; $\mathrm{NT}=$ not treated; $\mathrm{T}=$ treated. $*=$ eligible for identification and treatment of phantom cows. 
Table 1. Probabilities of events in a decision tree of phantom cow intervention on seasonal-calving dairy farms

\begin{tabular}{|c|c|c|}
\hline Node & Event & $P$-value \\
\hline 1 & Presented for $\mathrm{AI} \leq 14 \mathrm{~d}$ after $\mathrm{MSD}^{1}$ & 0.524 \\
\hline 2 & Conceived to AI $\leq 14 \mathrm{~d}$ after MSD & 0.700 \\
\hline $3 \mathrm{a}$ & Cows inseminated and conceived $\leq 14$ d after MSD (re-mated) & 0.116 \\
\hline $3 \mathrm{~b}$ & Cows inseminated but not conceived $\leq 14 \mathrm{~d}$ after MSD (re-mated) & 0.796 \\
\hline $3 \mathrm{c}$ & $\begin{array}{l}\text { Cows not inseminated } \leq 14 \mathrm{~d} \text { after MSD (mated) } \\
\text { Remained pregnant/conceived to mating } 15 \text { to } 49 \mathrm{~d} \text { after MSD }\end{array}$ & 0.950 \\
\hline $4 \mathrm{a}$ & Cows inseminated and conceived $\leq 14 \mathrm{~d}$ after MSD (remained pregnant) & 0.830 \\
\hline $4 \mathrm{~b}$ & Cows inseminated but did not conceive $\leq 14 \mathrm{~d}$ after MSD (conceived) & 0.600 \\
\hline $4 \mathrm{c}$ & $\begin{array}{l}\text { Cows not inseminated } \leq 14 \mathrm{~d} \text { after } \mathrm{MSD}^{-} \text {(conceived) } \\
\text { Presented for pregnancy diagnosis }\end{array}$ & 0.600 \\
\hline $5 \mathrm{a}$ & Eligible cows & 0.990 \\
\hline $5 \mathrm{~b}$ & $\begin{array}{l}\text { Ineligible cows } \\
\text { Diagnosed pregnant }{ }^{3}\end{array}$ & 0.010 \\
\hline $6 \mathrm{a}$ & Status A cows ( $>35$ d pregnant) & 1.000 \\
\hline $6 \mathrm{~b}$ & Status B cows ( $<35 \mathrm{~d}$ pregnant $)$ & 0.026 \\
\hline $6 c$ & $\begin{array}{l}\text { Status } \mathrm{C} \text { and } \mathrm{D} \text { cows (nonpregnant) } \\
\text { Pregnant at mating end date }\end{array}$ & 0.026 \\
\hline $7 \mathrm{a}$ & Status A cows, untreated & 0.988 \\
\hline $7 \mathrm{~b}$ & Status A cows, treated & 0.525 \\
\hline $7 \mathrm{c}$ & Status B cows, untreated & 0.988 \\
\hline $7 \mathrm{~d}$ & Status B cows, treated & 0.525 \\
\hline $7 \mathrm{e}$ & Status C cows, untreated & 0.611 \\
\hline $7 \mathrm{f}$ & Status C cows, treated & 0.763 \\
\hline $7 \mathrm{~g}$ & Status D cows, untreated & 0.500 \\
\hline $7 \mathrm{~h}$ & Status D cows, treated & 0.500 \\
\hline
\end{tabular}

ceived before mating end date were assumed to conceive $74 \mathrm{~d}$ after MSD (equivalent to true phantom cows).

Status B Cows. We assumed that status B cows conceived $32 \mathrm{~d}$ after MSD (the midpoint between d 15 and d 49 after MSD) and 50\% carried an AI-bred heifer fetus, which was replaced by a non-AI-bred fetus ("bobby calf") if the cow was treated and re-conceived. Status B cows that were treated and conceived before mating end date were also assumed to conceive $74 \mathrm{~d}$ after MSD.

Status C Cows. We assumed that 50\% of treated status C cows that were pregnant at the end of the mating period conceived and remained pregnant to FTAI and that $50 \%$ of fetuses were heifers (i.e., $25 \%$ of fetuses were AI-bred heifer calves). Untreated status C cows were mated naturally and therefore could not produce AI-bred calves. All cows in this group that were pregnant at the end of the mating period were assumed to conceive $74 \mathrm{~d}$ after MSD because enrolment occurred a mean $49 \mathrm{~d}$ after MSD and there was no difference between treated and untreated cows in the median enrolment to conception interval, so the overall median of $25 \mathrm{~d}$ was used [G. Chambers, M. O'Sullivan, and
C. Compton (EpiCentre, School of Veterinary Science, Massey University, Palmerston North, New Zealand), unpublished data].

Status $D$ Cows. We assumed that $50 \%$ of treated status D cows were pregnant at the end of the mating period regardless of treatment. Of the treated status $\mathrm{D}$ cows that were pregnant at the end of the mating period, we assumed 50\% conceived and remained pregnant to FTAI and that $50 \%$ of fetuses were heifers (i.e., $25 \%$ of fetuses were AI-bred heifer calves). Untreated status D cows were mated naturally and therefore could not produce AI-bred calves. Cows that were pregnant at mating end date were assumed to conceive $70 \mathrm{~d}$ after MSD (a mean interval of 21 d after d 49 after MSD) regardless of treatment.

\section{Estimating Outcome Values}

The probability of each terminal branch $\left(P_{i}\right)$ was the product of the probability values of each branch that preceded it. The sum of all $P_{i}$ was 1.00 . The weighted benefit of intervention per cow present at MSD was calculated by subtracting the cost of each outcome 
Table 2. Economic values used in a decision tree of phantom cow intervention on seasonal-calving dairy farms

\begin{tabular}{|c|c|c|}
\hline Component & $\begin{array}{l}\text { Estimated lactation } \\
\text { length }^{1}(\mathrm{~d})\end{array}$ & $\begin{array}{l}\text { Value } \\
(\mathrm{NZ} \$)\end{array}$ \\
\hline \multicolumn{3}{|l|}{ Costs } \\
\hline \multicolumn{3}{|l|}{ Treatment cost } \\
\hline Farm labor ${ }^{2}$ & & 0.33 \\
\hline Pregnancy diagnosis & & 2.50 \\
\hline Treatment program & & 65.00 \\
\hline \multicolumn{3}{|c|}{ Feed costs in the following season ${ }^{3,4}$} \\
\hline Status A, untreated & 293 & 615.30 \\
\hline Status A, treated & 226 & 474.60 \\
\hline Status B, untreated & 268 & 562.80 \\
\hline Status B, treated & 226 & 474.60 \\
\hline Status $\mathrm{C}$, untreated & 226 & 474.60 \\
\hline Status C, treated & 226 & 474.60 \\
\hline Status D, untreated & 230 & 483.00 \\
\hline Status D, treated & 230 & 483.00 \\
\hline \multicolumn{3}{|l|}{ Benefits } \\
\hline \multicolumn{3}{|l|}{ Cow value } \\
\hline Pregnant cow & & $1,529.00$ \\
\hline Nonpregnant cow & & 302.38 \\
\hline \multicolumn{3}{|c|}{ Value of milk produced in the following season ${ }^{5}$} \\
\hline Status A, untreated & 293 & $2,423.26$ \\
\hline Status A, treated & 226 & $1,869.14$ \\
\hline Status B, untreated & 268 & $2,216.50$ \\
\hline Status B, treated & 226 & $1,869.14$ \\
\hline Status C, untreated & 226 & $1,869.14$ \\
\hline Status C, treated & 230 & $1,869.14$ \\
\hline Status D, untreated & 230 & $1,902.22$ \\
\hline Status D, treated & 230 & $1,902.22$ \\
\hline \multicolumn{3}{|l|}{ Calf value at $4 \mathrm{~d}$ of age } \\
\hline AI-bred heifer calf & & 400.00 \\
\hline Other calves & & 35.00 \\
\hline
\end{tabular}

${ }^{1}$ In the season following intervention. The estimated interval from mating start date to conception (described in Materials and Methods) was subtracted from a maximum possible lactation length of $300 \mathrm{~d}$.

${ }^{2}$ One minute per cow presented to the treatment provider, at NZ $\$ 20$ per hour (at the time of the study, NZ $\$ 1$ $=\mathrm{US} \$ 0.6629)$.

${ }^{3}$ Cost of feed over and above maintenance requirements in the following lactation for cows pregnant at mating end date. The estimated lactation length was multiplied by the product of the marginal extra feed provided to lactating cows compared with nonlactating cows (assumed to be $7 \mathrm{~kg}$ of DM/d) and the feed cost (assumed to be $\mathrm{NZ} \$ 0.30 / \mathrm{kg}$ of $\mathrm{DM})$.

${ }^{4}$ Status indicates reproductive status of cow at enrolment on d 49 after mating start date (MSD). A $=\geq 35$ $\mathrm{d}$ pregnant; $\mathrm{B}=<35 \mathrm{~d}$ pregnant; $\mathrm{C}=$ inseminated $\leq 14 \mathrm{~d}$ after MSD and nonpregnant (phantom cow); $\mathrm{D}=$ inseminated $\leq 14 \mathrm{~d}$ after MSD and conceived but subsequently re-inseminated and terminated pregnancy or failed to conceive but subsequently re-inseminated or not inseminated $\leq 14 \mathrm{~d}$ after MSD.

${ }^{5}$ Value of milk in the following lactation for cows pregnant at mating end date. The estimated lactation length was multiplied by the product of the mean daily milk yield (1.321 kg of milk solids) and the milk price (NZ\$6.26 per $\mathrm{kg}$ of milk solids).

from its benefit (Table 2) and multiplying the difference by the outcome's probability as follows: Netbenefit $=\sum_{i=1}^{n} P_{i}\left(\right.$ Benefit $_{i}-$ Cost $\left._{i}\right)$, where $n$ is the number of terminal nodes.

\section{Decision-Tree Validation}

Selected terminal branch probability values were summed to evaluate the overall fit of the decision trees. The proportion of cows present at MSD determined to be pregnant by d 49 after MSD and at the end of mat- ing were compared with estimated national means. The number of cows required to be submitted for veterinary pregnancy diagnosis to find one true phantom cow, the proportion of true phantom cows (status C) that were identified and treated, and the proportion of cows treated as phantom cows that were not true phantom cows (were already pregnant or were not inseminated $\leq 14 \mathrm{~d}$ after MSD and were not pregnant) were also calculated from terminal branch probability values. To estimate the effect of phantom cow intervention on cows that were already pregnant at d 49 but were inadvertently treated, we compared the probability of status $\mathrm{A}$ and $\mathrm{B}$ cows being pregnant at the end of the 
Table 3. Variables and their ranges tested in a sensitivity analysis decision tree of phantom cow intervention on seasonal-calving dairy farms

\begin{tabular}{|c|c|c|c|}
\hline Variable & Default & Minimum & Maximum \\
\hline Phantom cow prevalence $^{1}$ & 0.090 & 0.010 & 0.200 \\
\hline PD sensitivity ${ }^{2}$ & 1.000 & 0.900 & 1.000 \\
\hline PD specificity & 0.974 & 0.800 & 1.000 \\
\hline Probability of being presented for PD (eligible cows) ${ }^{3}$ & 0.990 & 0.900 & 1.000 \\
\hline Probability of being presented for PD (ineligible cows) ${ }^{4}$ & 0.010 & 0.000 & 0.100 \\
\hline Mean daily milk yield ( $\mathrm{kg}$ of milk solids/d) & 1.321 & 1.000 & 3.000 \\
\hline Milk value ( $\mathrm{NZ} \$^{5} / \mathrm{kg}$ of milk solids) & 6.26 & 3.50 & 9.00 \\
\hline Feed cost $(\mathrm{NZ} \$ / \mathrm{kg}$ of $\mathrm{DM})$ & 0.30 & 0.20 & 0.50 \\
\hline Treatment cost $(\mathrm{NZ} \$ /$ cow $)$ & 65.00 & 50.00 & 100.00 \\
\hline Market value of pregnant cow $(\mathrm{NZ} \$)$ & 1,529 & 1,000 & 2,500 \\
\hline Market value of artificially bred heifer calf $(\mathrm{NZ} \$)$ & 400 & 0 & 1,000 \\
\hline
\end{tabular}

${ }^{1}$ Defined as the proportion of cows that were inseminated $\leq 14 \mathrm{~d}$ after mating start date (MSD), did not return to estrus, and were presented for pregnancy diagnosis at approximately $49 \mathrm{~d}$ after MSD that were diagnosed as phantom cows.

${ }^{2} \mathrm{PD}=$ pregnancy diagnosis.

${ }^{3}$ Eligible cows were cows that were inseminated $\leq 14 \mathrm{~d}$ after MSD, did not return to estrus, and were presented for pregnancy diagnosis at approximately $49 \mathrm{~d}$ after MSD.

${ }^{4}$ Ineligible cows were all other cows.

${ }^{5}$ At the time of the study, NZ $\$ 1=\mathrm{US} \$ 0.6629$.

seasonal mating period under no treatment and under treatment.

\section{Sensitivity Analysis}

The influence of key parameters on the economics of phantom cow intervention were explored by sensitivity analysis. Minimum and maximum values were defined for 12 parameters of interest and the range was divided into 1,000 values (Table 3 ). The net value was calculated for each value of the variable of interest while holding all other variables at their default values. The effects of changes in variable estimates on the net value of a phantom cow intervention program were demonstrated visually in a tornado plot. Economic break-even points were calculated for each variable of interest by defining the variable value at which the net return became positive.

\section{RESULTS}

Using the baseline assumptions about herd reproductive performance, the decision tree predicted that $36.0 \%, 34.6 \%, 3.2 \%$, and $26.2 \%$ of cows present at MSD would be status A-D, respectively, at d 49 after MSD, connoting an estimated $70.6 \%$ of cows present at MSD were pregnant (status A or B) at d 49 after MSD. One in every 12 cows presented by the farmer for pregnancy diagnosis on d 49 was a true phantom cow given an assumed phantom cow prevalence of $9.0 \%$ in cows that were inseminated $\leq 14 \mathrm{~d}$ after MSD but not subsequently detected in estrus and allowing for ineligible cows being presented for pregnancy diagnosis.
An estimated $96.4 \%$ of true phantom cows (status C) were successfully identified as phantom cows after being presented by the farmer and diagnosed nonpregnant. On the other hand, of the cows diagnosed and treated as phantom cows, $16.1 \%$ were not true phantom cows. These false diagnoses comprised status B cows $(9.2 \%$ of the cows diagnosed and treated as phantom cows) and status D cows (6.9\% of the cows diagnosed and treated as phantom cows). No status A cows were incorrectly treated as phantom cows because pregnancy diagnosis sensitivity was assumed to be $100 \%$.

The net economic return from treating phantom cows with a progesterone-based synchrony program was $\mathrm{NZ} \$ 4.451$ (at the time of the study, $\mathrm{NZ} \$ 1=\mathrm{US} \$ 0.6629$ ) per cow present at MSD. For the no-treatment and treatment scenarios, $84.8 \%$ and $85.1 \%$ of cows present at MSD were estimated to be pregnant by mating end date, respectively. Termination of pregnancies caused by inadvertent treatment of cows that were already pregnant at d 49 (status A or B) reduced the probability of their being pregnant at the end of the seasonal mating period from $98.8 \%$ to $98.6 \%$.

In the sensitivity analysis (Figure 3 ), the sensitivity of pregnancy diagnosis, the probability of the farmer presenting ineligible cows for pregnancy diagnosis, and the prevalence of phantom cows had the largest effects on the net return of phantom cow intervention. When all covariates were held at their default values, it was shown that sensitivity of pregnancy diagnosis had to be greater than $99.2 \%$, the probability of ineligible cows being presented by the farmer had to be less than $1.8 \%$, and the prevalence of phantom cows had to be greater than $5.5 \%$ in order for the farmer to break even on 


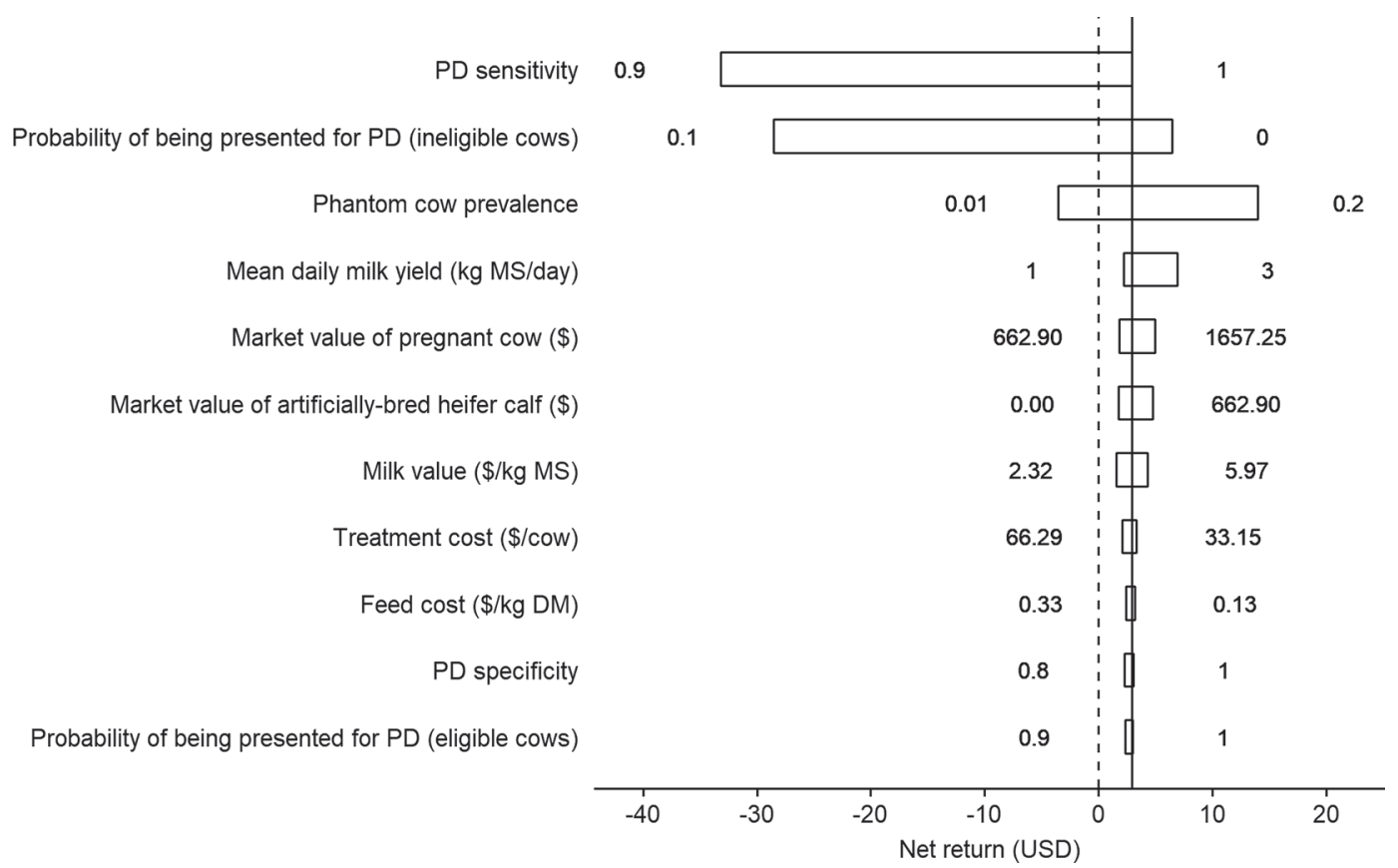

Figure 3. Tornado plot of the net returns [NZ\$/cow (at the time of the study, NZ\$1 = US\$0.6629) present at mating start date, MSD] from a sensitivity analysis of a phantom cow intervention program on a seasonal-calving New Zealand dairy farm. PD $=$ pregnancy diagnosis Prevalence was defined as the proportion of cows that were inseminated $\leq 14 \mathrm{~d}$ after mating start date, were not subsequently detected in estrus and were presented for pregnancy diagnosis at approximately $49 \mathrm{~d}$ after MSD that were diagnosed as phantom cows. Eligible cows were inseminated $\leq 14 \mathrm{~d}$ after mating start date, did not return to estrus, and were presented for pregnancy diagnosis at approximately $49 \mathrm{~d}$ after MSD. Ineligible cows were all other cows.

a phantom cow intervention program. When farmers were assumed to have $100 \%$ accuracy in presenting eligible cows for pregnancy diagnosis, the net economic return from phantom cow intervention was $\mathrm{NZ} \$ 9.83$ per cow present at MSD.

\section{DISCUSSION}

To our knowledge, this is the first published study evaluating the economic return of phantom cow intervention and our results demonstrated that treating phantom cows with a progesterone-based synchrony program is economically viable on a seasonal-calving dairy farm under specific conditions. In herds with a $9 \%$ prevalence of phantom cows among cows inseminated in the first $14 \mathrm{~d}$ of the mating period and not subsequently detected in estrus, the net benefit was estimated to be at least $\mathrm{NZ} \$ 4.451$ per cow present at MSD, with higher rates of return observed as the accuracy of the farmer in presenting cows for pregnancy diagnosis increased. Although these estimates are specific to the inputs we used, farmers and animal health advisors can easily adapt the decision tree variables to more closely match their unique farm situation.

The economic return of phantom cow intervention was unsurprisingly highly dependent on the sensitivity of veterinary pregnancy diagnosis. A previous study in seasonal-calving Australian dairy herds estimated the sensitivity of ultrasonographic pregnancy diagnosis at $93.9 \%$ at a minimum of $35 \mathrm{~d}$ postinsemination (Shephard and Morton, 2018) and in the randomized controlled trial upon which the present study is based, the sensitivity of pregnancy diagnosis was not estimated, but we found that 7/189 (4\%) phantom cows allocated to the control group were $\geq 35 \mathrm{~d}$ pregnant at the initial pregnancy diagnosis (Chambers et al., 2020). Although both of these studies found sensitivities below the $99.2 \%$ needed to achieve the economic break-even for phantom cow intervention, it is worth noting another study in non-seasonal-calving North American dairy cows found that the sensitivity of transrectal ultrasonography for diagnosing pregnancy increased from $74.5 \%$ at d 24 postinsemination to $100 \%$ at d 29 postinsemination (Romano et al., 2006). This suggests that diagnostic sensitivity of pregnancy diagnostic is highly influenced by the stage in pregnancy as well as variation in skill between individual operators. It is therefore essential that operators consider the accuracy of pregnancy diagnosis when discussing a phantom cow intervention program with a dairy farmer. In particular, it is important to clearly define cows that should be presented for pregnancy diagnosis and choose an appro- 
priate date (or dates) to conduct pregnancy diagnosis so that eligible cows are at a stage of pregnancy that maximizes pregnancy diagnosis sensitivity.

In the present study, the economics of intervention were calculated only for cows inseminated in the first $14 \mathrm{~d}$ of the mating period based on the assumption that phantom cow intervention is typically limited to cows inseminated early in the mating period on seasonal-calving farms because of the need to treat and inseminate phantom cows before mating end date. It is unclear if the same results would occur if the intervention was modified and eligibility extended to cows that were inseminated after $14 \mathrm{~d}$, but it is likely that the returns would be comparable if the farmer applies the same standard of estrus detection and cow selection. Particular care in extending the window of eligibility must be taken in herds that introduce bulls immediately after an AI period of 5 to 6 wk since any cows that fail to conceive to AI may become pregnant to natural mating and therefore be at an early stage of gestation when pregnancy examination is performed. This may increase the risk of inadvertently treating status B cows (cows that are $<35 \mathrm{~d}$ pregnant at the initial pregnancy diagnosis) and subsequently aborting their pregnancy. Focusing on cows that were bred in the early mating period is expected to be the most fruitful period for identifying phantom cows, especially if anestrus cows were treated and inseminated by FTAI during this period, because treatment for anestrus has been shown to be a significant phantom cow risk factor (Cuttance and Mason, 2015).

Our analysis confirmed that the unintended presentation of ineligible cows by the farmer for pregnancy diagnosis has a large bearing on the economic returns from phantom cow intervention. Our definition of ineligible included cows that were mated and conceived after the period of interest (status B) as well as cows that were not inseminated in the period of interest and were truly nonpregnant at the time of pregnancy diagnosis (status D). Although we assumed that the only benefits from inadvertently treating status D cows were gaining $25 \%$ AI-bred heifer calves, it is unclear whether treatment with a progesterone-based synchrony program on d 49 after MSD improves their chances of being pregnant by the end of mating either through AI or natural mating. We may therefore have underestimated the true benefit of the method of phantom cow intervention used in this study.

Our model accounted for the risk that cows that were truly pregnant on d 49 after MSD were classified as nonpregnant either due to farmer cow selection error or pregnancy diagnosis error. Treating these cows with synchrony programs that abort pregnancy is likely to lead to significant economic costs given their reduced chance of re-conceiving by the end of mating, the delayed calving date if they re-conceive and resulting shorter lactation in the next season, and the potential loss of a valuable, AI-bred calf. In the previous randomized controlled trial, $5.8 \%$ of cows in the control group were subsequently determined to have been $<35$ d pregnant at the initial pregnancy diagnosis (status B; Chambers et al., 2020). Similarly, Cuttance and Mason (2015) found $6.4 \%$ of cows diagnosed as phantom cows were subsequently confirmed to have been $<35 \mathrm{~d}$ pregnant at enrolment. These cows were all presented on one of 12 farms enrolled in the latter study, which again highlights the need to make dairy farmers aware of the importance of accurate estrus detection, maintaining excellent herd records, and accurate cow selection before commencing a phantom cow intervention program. Animal health advisors may have to make a judgment of each farmer's capabilities when using our model to determine the cost-effectiveness of phantom cow intervention programs.

On a given dairy farm, phantom cow intervention is more likely to be profitable as the prevalence of phantom cows increases because of the greater return on investment from conducting pregnancy diagnosis on cows that were inseminated, but not subsequently observed in heat. While we recognize that the prevalence of phantom cows cannot be determined until after pregnancy diagnosis, advisors can assess whether the herd has significant numbers of cows with known risk factors including having a BCS $<4.5$ when measured on a 10-point scale (Roche et al., 2004), a history of treatment for being not detected in estrus before MSD in the same season, being a purebred cow, being 2 or $>6 \mathrm{yr}$ of age, and having a short calving to mating interval (Cuttance and Mason, 2015). It is also worth noting that most other variables tested by sensitivity analysis had relatively little effect on the net return of phantom cow intervention, which suggests that treatment of phantom cows with a progesterone-based synchrony program is likely to be profitable regardless of the specificity of pregnancy diagnosis, current market animal and milk values, mean daily milk yield, and the costs of treatment and feed.

Decision-tree analysis was deemed the most suitable technique for estimating the economic value of phantom cow intervention, but it is limited by the need to specify event probabilities and economic values (Ngategize et al., 1986). Indeed, the complexity of dairy herd reproduction necessitated large decision trees with multiple nodes and many assumptions. For example, it was necessary to approximate the probability of conception to AI as measured within 1 to $14 \mathrm{~d}$ of AI. This probability is unknown because of the delay between conception and the ability to detect a pregnancy. It has been esti- 
mated that $90 \%$ of inseminations result in conception, but because the majority of embryonic deaths occur within $16 \mathrm{~d}$ of conception, the apparent conception risk is substantially lower by the time of pregnancy diagnosis (Diskin et al., 2012). In the absence of a $100 \%$ accurate method for detecting pregnancy immediately after conception, the true performance of phantom cow intervention cannot be measured and was therefore calculated from the results of the randomized controlled trial. Intervals from MSD to conception and lactation lengths were estimated for all cows except for true phantom cows. The decision trees were constructed on the assumption that all pregnant cows were retained in the herd and calved in the following season. Although we advise farmers to only present cows they do not intend to cull, it is possible that culling and death over the dry period and in the following lactation may diminish the net return of phantom cow intervention. Further work is necessary to validate the estimates by comparison with observed intervals in commercial dairy herds.

Although several simplifying assumptions were made in representing herd reproductive performance in the decision tree, our validation showed that the decision tree generated reproductive outcomes consistent with those of a typical spring-calving herd. The assumptions made across all nodes before $\mathrm{d} 49$ of the mating period resulted in an estimated $70.6 \%$ of cows present at MSD being pregnant by $\mathrm{d} 49$, which is similar to the estimated mean proportion of New Zealand cows that were pregnant by d 42 in the 2017-2018 season of $66.1 \%$ (DairyNZ and Livestock Improvement Corporation, 2018). The decision trees also estimated that $84.8 \%$ and $85.1 \%$ of cows present at MSD were estimated to be pregnant by mating end date under no-treatment and treatment scenarios, respectively, which approximates the estimated $82.4 \%$ of cows milked twice daily and $87.2 \%$ of cows milked once daily that were pregnant by mating end date over the seasons beginning in 2014-2016 (Hemming et al., 2018). However, we recognize that these assumptions may not be appropriate for farms that have significantly higher or lower reproductive performance indices than the industry averages.

As previously highlighted, the results from our analysis were based on an average herd and average economic values. Although we did test the effect of varying key parameters through a sensitivity analysis, it should be noted that this was performed for each variable individually while holding the other covariates at their default values. We did not test the combined effect of varying several parameters simultaneously nor the potential interactions between decision-tree parameters. For example, it was assumed that the probability of an ineligible cow being presented by the farmer was not conditional on whether the cow was inseminated in the first $14 \mathrm{~d}$ of the mating period. An electronic tool is under construction and will be made available to allow animal health advisors to modify parameters to suit their farm scenarios. However, further work is still needed to validate the decision-tree model by comparing the predictions for a wider range of farm scenarios against the actual reproductive performance of phantom and nonphantom cows on farms during intervention and in the following season.

\section{CONCLUSIONS}

Treatment of phantom cows on seasonal-calving dairy farms with a progesterone-based synchrony program is expected to be economically viable, but accurate pregnancy diagnosis and cow selection are essential to the success of phantom cow intervention. Animal health advisors can select farms likely to have a favorable net return based on presence of risk factors that indicate a higher phantom cow prevalence.

\section{ACKNOWLEDGMENTS}

The authors are grateful to the farmers for agreeing to participate in the study. The sponsorship provided by Zoetis (Auckland, New Zealand) was greatly appreciated. G. Chambers is employed by Zoetis NZ. The randomized controlled trial that this article is based on was sponsored by Zoetis NZ. The other authors have not stated any conflicts of interest.

\section{REFERENCES}

Bates, A. J., A. G. Kenyon, R. A. Laven, and J. C. McDowell. 2016. Resynchronising returns to service in anoestrous dairy cows in the South Island of New Zealand. N. Z. Vet. J. 64:268-274. https://doi .org/10.1080/00480169.2016.1184108.

Breukelman, S. P., O. Szenci, J. F. Beckers, H. Kindahl, E. J. Mulder, F. H. Jonker, B. van der Weijden, D. Revy, K. Pogany, J. Sulon, I. Nemedi, and M. A. Taverne. 2005. Ultrasonographic appearance of the conceptus, fetal heart rate and profiles of pregnancy-associated glycoproteins (PAG) and prostaglandin F2alpha-metabolite (PGF2alpha-metabolite) after induction of fetal death with aglepristone during early gestation in cattle. Theriogenology 64:917-933. https://doi.org/10.1016/j.theriogenology.2004.12.016.

Bryan, M. A., G. Bo, R. J. Mapletoft, and F. R. Emslie. 2013. The use of equine chorionic gonadotropin in the treatment of anestrous dairy cows in gonadotropin-releasing hormone/progesterone protocols of 6 or 7 days. J. Dairy Sci. 96:122-131. https://doi.org/10 $.3168 / \mathrm{jds} .2012-5452$.

Cavalieri, J., V. Eagles, M. Ryan, and K. L. Macmillan. 2003a. Comparison of four methods for detection of oestrus in dairy cows with resynchronised oestrous cycles. Aust. Vet. J. 81:422-425. https:// doi.org/10.1111/j.1751-0813.2003.tb11553.x.

Cavalieri, J., J. M. Morton, D. P. Nation, G. Hepworth, S. Pino, A. Rabiee, and K. L. Macmillan. 2003b. Phantom Cows: Predisposing factors, causes and treatment strategies that have been attempted to reduce the prevalence within herds. Pages $365-388$ in Proc. 20th 
Annual Conference of the Society of Dairy Cattle Veterinarians of the New Zealand Veterinary Association. VetLearn.

Chambers, G. P., M. L. O'Sullivan, and C. Compton. 2020. Effect of treatment of phantom cows with a progesterone-based synchrony programme. N. Z. Vet. J. 2020:1-11. https://doi.org/10.1080/ 00480169.2020 .1745109$.

Cuttance, E. L., and W. A. Mason. 2015. Risk factors for and reproductive outcomes of phantom cows on New Zealand dairy farms. N. Z. Vet. J. 63:276-283. https://doi.org/10.1080/00480169.2015 .1031292

DairyNZ. 2013. Liveweight economic model. Accessed Apr. 29, 2019. https://www.dairynz.co.nz/media/928750/Liveweight-Economic -Model.pdf

DairyNZ and Livestock Improvement Corporation. 2018. New Zealand Dairy Statistics 2017-18. Accessed May 4, 2019. https:/ www .dairynz.co.nz/media/5790451/nz-dairy-statistics-2017-18.pdf

Day, A. M. 1977. Cloprostenol for termination of pregnancy in cattle. B) The induction of abortion. N. Z. Vet. J. 25:139-144. https://doi .org/10.1080/00480169.1977.34386.

Dijkhuizen, A. A., R. B. M. Huirne, and A. W. Jalvingh. 1995. Economic analysis of animal diseases and their control. Prev. Vet. Med. 25:135-149. https://doi.org/10.1016/0167-5877(95)00535-8.

Diskin, M. G., M. H. Parr, and D. G. Morris. 2012. Embryo death in cattle: An update. Reprod. Fertil. Dev. 24:244-251. https://doi .org/10.1071/RD11914

Federated Farmers and Rabobank. 2018. Farming remuneration summary report 2017/18. Accessed May 4, 2019. www.fedfarm.org.nz.

Hemming, N. V., L. R. McNaughton, and C. Couldrey. 2018. Brief communication: Reproductive performance of herds milked once a day all season compared with herds milked twice a day all season. N. Z. J. Anim. Sci. Reprod. 78:170-172.

Inland Revenue. 2018. National Average Market Values of Specified Livestock Determination, 2018. Accessed Jun. 25, 2019. https:/ /www.classic.ird.govt.nz/technical-tax/determinations/livestock/ national-averages/livestock-nationalavemarketvalues-2018.html.

Interest.co.nz. 2019. Cow Prices. Accessed Jun. 25, 2019. https://www interest.co.nz/rural/beef/cow-prime.

Macmillan, K. L., and R. J. Curnow. 1977. Tail painting-A simple form of oestrus detection in New Zealand dairy herds. N. Z. J. Exp. Agric. 5:357-361. https://doi.org/10.1080/03015521.1977 10425996

McDougall, S., and C. W. Compton. 2006. Reproductive performance in the subsequent lactation of dairy cows previously treated for failure to be detected in oestrus. N. Z. Vet. J. 54:132-140. https:/ /doi.org/10.1080/00480169.2006.36625.

McDougall, S., F. M. Rhodes, and G. Verkerk. 2005. Pregnancy loss in dairy cattle in the Waikato region of New Zealand. N. Z. Vet. J. 53:279-287. https://doi.org/10.1080/00480169.2005.36561.

Ngategize, P. K., J. B. Kaneene, S. B. Harsh, P. C. Bartlett, and E. L. Mather. 1986. Decision analysis in animal health programs: Merits and limitations. Prev. Vet. Med. 4:187-197. https://doi.org/10 1016/0167-5877(86)90022-X.

R Core Team. 2017. R: A language and environment for statistical computing. Version 3.4.3. Vienna, Austria.

Roche, J. R., P. G. Dillon, C. R. Stockdale, L. H. Baumgard, and M. J. VanBaale. 2004. Relationships among international body condition scoring systems. J. Dairy Sci. 87:3076-3079. https://doi.org/ 10.3168/jds.S0022-0302(04)73441-4.

Romano, J. E., J. A. Thompson, D. W. Forrest, M. E. Westhusin, M. A. Tomaszweski, and D. C. Kraemer. 2006. Early pregnancy diagnosis by transrectal ultrasonography in dairy cattle. Theriogenology 66:1034-1041. https://doi.org/10.1016/j.theriogenology .2006.02.044.

Sheldon, I. M., G. S. Lewis, S. LeBlanc, and R. O. Gilbert. 2006. Defining postpartum uterine disease in cattle. Theriogenology 65:1516-1530. https://doi.org/10.1016/j.theriogenology.2005.08 .021 .

Shephard, R. W., and J. M. Morton. 2018. Estimation of sensitivity and specificity of pregnancy diagnosis using transrectal ultrasonography and ELISA for pregnancy-associated glycoprotein in dairy cows using a Bayesian latent class model. N. Z. Vet. J. 66:30-36. https://doi.org/10.1080/00480169.2017.1391723.

Sturman, H., E. A. Oltenacu, and R. H. Foote. 2000. Importance of inseminating only cows in estrus. Theriogenology 53:1657-1667. https://doi.org/10.1016/S0093-691X(00)00305-8.

Thomas, I., and H. Dobson. 1989. Oestrus during pregnancy in the cow. Vet. Rec. 124:387-390. https://doi.org/10.1136/vr.124.15 .387 .

Vanholder, T., G. Opsomer, and A. de Kruif. 2006. Aetiology and pathogenesis of cystic ovarian follicles in dairy cattle: A review. Reprod. Nutr. Dev. 46:105-119. https://doi.org/10.1051/rnd: 2006003.

Verkerk, G. 2003. Pasture-based dairying: Challenges and rewards for New Zealand producers. Theriogenology 59:553-561. https://doi .org/10.1016/S0093-691X(02)01239-6.

\section{ORCIDS}

G. P. Chambers (ํ) https://orcid.org/0000-0001-7864-0057

M. L. O'Sullivan ( https://orcid.org/0000-0002-7057-2085

M. C. Gates @ https://orcid.org/0000-0002-7790-1945

\section{APPENDIX}

\section{Phantom Cow Intervention Study- Supplementary Information}

The intervention study is described in full by Chambers et al. (2020). The aim was to determine the effect of a progesterone-based synchrony program on the daily hazard of conception and the odds of being pregnant at the end of the seasonal mating period in cows not observed in estrus within 35 to $49 \mathrm{~d}$ of insemination and that were diagnosed nonpregnant (phantom cows). Cows from 14 commercial dairy farms located in the Waitaki District of New Zealand were enrolled in a randomized controlled study in the 2012-2013 dairy season that was designed to determine the efficacy of a hormonal intervention program. The dairy farms were a convenience sample of farms serviced by a single veterinary business. All study farms were pasture based and seasonal, with calving occurring in the spring. All farmers artificially inseminated cows to detected estrus for a minimum of $35 \mathrm{~d}$ after MSD, after which bulls were introduced to the cows. Estrus detection by application of tail paint was conducted until at least the date of phantom cow enrolment at the first pregnancy diagnosis. Enrolment was restricted to cows inseminated $\leq 14 \mathrm{~d}$ after MSD so that treatment and insemination of phantom cows could be achieved within 10 wk of MSD, by which time the mating period ends on many seasonal dairy farms.

The study commenced approximately 7 wk after each farm's MSD, when all cows that had been inseminated in the first $14 \mathrm{~d}$ of mating and had not subsequently been detected in estrus were pregnancy diagnosed using transrectal ultrasonography. Cows that were not 
detectably pregnant were classified as phantom cows. The reproductive tract and conceptus were ultrasonographically and manually examined by a veterinarian for pathology. Cows diagnosed with pyometra at the time of enrolment $(\mathrm{n}=7)$, defined as the presence of a CL in an ovary, accumulation of mixed echodensity fluid in the uterine lumen, and distension of the uterus (Sheldon et al., 2006), were excluded. Cows in which a nonviable fetus was detected $(\mathrm{n}=32)$, defined as segregation of the allantochorionic membrane from the endometrium and lack of a fetal heart beat (Breukelman et al., 2005), were enrolled. The first eligible phantom cow on each farm was allocated to the treatment group and the remaining cows were alternately allocated within farm to either the control or the treatment group.

Cows allocated to the control group received no further treatment and were mated naturally by bulls to spontaneous estrus. Cows allocated to the treatment group were immediately enrolled in a 10-d synchrony program. Treatment consisted of intramuscular injection of $8 \mu \mathrm{g}$ of buserelin (2 $\mathrm{mL}$ of Receptal, MSD Animal Health, Wellington, New Zealand) and insertion of an intravaginal device containing $1.38 \mathrm{~g}$ progesterone (CIDR Cattle Insert, Zoetis New Zealand Ltd., Auckland, New Zealand), followed 7 d later by intramuscular injections of $25 \mathrm{mg}$ of dinoprost $(5 \mathrm{~mL}$ of Lutalyse, Zoetis New Zealand Ltd., Auckland, New Zealand) and $400 \mathrm{IU}$ of equine chorionic gonadotrophin (2 mL of Pregnecol, Bayer, Auckland, New Zealand) and removal of the intravaginal device, followed $2 \mathrm{~d}$ later by intramuscular injection of $8 \mu \mathrm{g}$ of buserelin $(2$ $\mathrm{mL}$ of Receptal), and ending with FTAI approximately $16 \mathrm{~h}$ after buserelin injection. Treatment group cows were separated from bulls on the day before FTAI and reintroduced after FTAI. Cows in the treatment group diagnosed with follicular ovarian cysts at enrolment (n $=9$ ), defined as follicles with a diameter $\geq 20 \mathrm{~mm}$ that were present on one or both ovaries in the absence of any active luteal tissue and that clearly interfered with normal ovarian cyclicity (Vanholder et al., 2006), were enrolled but were given an additional $12 \mu \mathrm{g}$ of buserelin on d 0.

Pregnancy status and date of conception were determined ultrasonographically for all study cows by a veterinarian during routine herd pregnancy diagnosis visits.

A multivariable marginal Cox regression model was constructed to model the effect of treatment on the hazard of conception and a generalized estimating equation with a binomial link was constructed to determine the effect of treatment on the proportion of phantom cows pregnant at the end of mating.

\section{Assumptions Used for Determining Decision Tree Node Probabilities}

Node 1: Presented for $A I \leq 14$ d After MSD. The probability of being presented for AI was calculated by multiplying the estimated 2018 New Zealand dairy industry mean 21-d submission rate (DairyNZ and Livestock Improvement Corporation, 2018) by twothirds (to estimate the submission rate over the first 14 d), creating a probability of 0.524 .

Node 2: Conceived to AI. The estimated 2018 New Zealand dairy industry conception rate to AI was $51.6 \%$ (DairyNZ and Livestock Improvement Corporation, 2018), but that is calculated at the time of final pregnancy diagnosis, after embryonic deaths have occurred. The decision tree quantifies the probability of conception at d 15 after MSD, which will be higher than at final pregnancy diagnosis but is unquantifiable. We estimated the probability of conception to be 0.700 .

Node 3: Mated 15 to 49 d After MSD. The sensitivity $\left(S e_{H D}\right)$ and specificity $\left(S p_{H D}\right)$ of estrus detection were assumed to be 0.913 and 0.926 , respectively (Cavalieri et al., 2003a). It was assumed that these cows may be mated artificially or naturally by bulls.

For status A cows, we assumed that the probability of displaying estrus $(\gamma)$ was 0.050 (Thomas and Dobson, 1989). The probability of being mated 14 to $49 \mathrm{~d}$ after MSD (node 3a) was calculated with the formula $P_{3 a}=\gamma S e_{H D}+(1-\gamma)\left(1-S p_{H D}\right)$, producing a probability of 0.116 .

For cows that were inseminated $\leq 14 \mathrm{~d}$ after MSD but did not conceive, the proportion that were mated 15 to $49 \mathrm{~d}$ after MSD (node 3b) was manipulated to generate a $9.0 \%$ phantom cow prevalence $(\pi)$ in cows inseminated $\leq 14 \mathrm{~d}$ after MSD and not subsequently detected in estrus by $d 49$ with the formula $P_{3 b}=1-\frac{\left(\frac{\pi}{1-\pi}\right) P_{1} P_{2}\left(1-P_{3 a}\right)}{P_{1}\left(1-P_{2}\right)}$, yielding a probability of 0.796 .

For cows that were not inseminated $\leq 14$ d after MSD, we assumed the probability of being mated 15 to $49 \mathrm{~d}$ after MSD (node 3c) was 0.950.

Node 4: Remained Pregnant/Conceived to Mating. It was assumed that status A cows that were mated again 15 to $49 \mathrm{~d}$ after MSD had a probability of remaining pregnant (node 4a) of 0.830 (Sturman et al., 2000), and cows that did not remain pregnant did not re-conceive before d 49. For all other cows that were mated 15 to $49 \mathrm{~d}$ after MSD, the probability of conception (nodes $4 \mathrm{~b}$ and $4 \mathrm{c}$ ) was assumed to be 0.600 . This was set higher than the national mean to account for early embryonic death. 
Node 5: Presented for Pregnancy Diagnosis. The probabilities of eligible (node 5a) and ineligible (node $5 \mathrm{~b}$ ) cows being presented were estimated.

Node 6: Diagnosed Pregnant. The sensitivity $\left(S e_{P D}\right)$ and specificity $\left(S p_{P D}\right)$ of pregnancy diagnosis were assumed to be 1 and 0.974 , respectively (Romano et al., 2006). The probability of status A cows being diagnosed as pregnant (true positive, node 6a) was assumed to be $S e_{P D}=1$. The probability of status B cows being diagnosed pregnant ("false" positives, node $6 \mathrm{~b}$ ) was assumed to be $1-S p_{P D}=0.026$, with the remainder diagnosed nonpregnant and assumed to be phantom cows. Similarly, the probability of status C and $\mathrm{D}$ cows being diagnosed pregnant (false positives, node 6c) was assumed to be 0.026 .

Node 7: Pregnant at Mating End Date. Previous research found cloprostenol to terminate $100 \%$ of pregnancies in cows that were 35 to $60 \mathrm{~d}$ pregnant (Day, 1977). We assumed the probability of terminating pregnancy $(\tau)$ by treating a pregnant cow to be 0.950 , given $1 / 206$ cows in the treatment group of the randomized controlled trial was subsequently found to have conceived before enrolment and remain pregnant despite treatment. The probability of a cow whose pregnancy was terminated re-conceiving before mating end date $(\rho)$ was assumed to be 0.500 (McDougall et al., 2005).

For untreated status A cows, it was assumed that the probability of being pregnant at mating end date (node 7a) was 0.988 (Cuttance and Mason, 2015). For treated status A cows, the probability of being pregnant at mating end date (node $7 \mathrm{~b}$ ) was calculated with the formula $P_{7 b}=(1-\tau)+\tau \rho$, producing a probability of 0.525 .

The same probabilities were applied to untreated and treated status B cows (nodes $7 \mathrm{c}$ and $7 \mathrm{~d}$ ).

For status $\mathrm{C}$ cows, treated and untreated phantom cows had probabilities of conceiving by the end of the seasonal mating period of 0.728 and 0.611 respectively in the randomized controlled trial. However, the effect of treatment was likely to have been underestimated for true phantom cows. Subsequent pregnancy diagnosis revealed $9.0 \%$ of cows in the control group were pregnant at enrolment and they were excluded from the analysis. The prevalence of cows that were already pregnant at enrolment on d 49 in the treatment group is unknown but expected to be comparable to the control group because cows were randomly allocated to treatment groups. Exposure to $\mathrm{PGF}_{2 \alpha}$ and $\mathrm{AI}$ likely terminated their pregnancies before they could be detected (the single cow that remained pregnant was excluded from analysis in the intervention study). The probability of untreated status $\mathrm{C}$ cows conceiving (node
$7 \mathrm{e})$ remained at 0.611 . To estimate the probability of conception for true phantom cows (node $7 \mathrm{f}$ ), we assumed that the apparent probability of treated cows conceiving $\left(P_{a p p}\right)$ was 0.728 , the probability of being already pregnant at enrolment $(\alpha)$ was 0.09 , and the risk of re-conceiving between pregnancy termination and the end of the seasonal mating period $(\rho)$ was 0.500 (McDougall et al., 2005). The risk of being pregnant at mating end date for a status $\mathrm{C}$ cow was calculated with the formula: $P_{7 f}=\frac{P_{a p p}}{1-\alpha \rho}$, resulting in a probability of 0.763

For status D cows, we assumed that treatment had no effect on the probability of conceiving by the end of mating and untreated and treated status D cows were both assigned a probability of 0.500 (nodes $7 \mathrm{~g}$ and $7 \mathrm{~h}$ ).

\section{Estimating Economic Values}

The costs of the phantom cow intervention program were grouped into treatment costs (farm labor, pregnancy diagnosis, and treatment) and feed costs (the extra daily feed allocated to a lactating cow over a dry cow). The benefits were grouped into cow value, value of milk produced in the following season, and calf value. Economic values were based on national statistics and expert opinion (Table 2).

Treatment Costs. These comprised, in chronological order, the costs of farm labor associated with separating animals for enrolment, pregnancy diagnosis, and treatment and insemination. Labor was priced at $\mathrm{NZ} \$ 0.33$, based on one farm staff member spending 1 min per cow presented to the service provider on d 49 after MSD, at an hourly rate of NZ $\$ 20 / \mathrm{h}$ (Federated Farmers and Rabobank, 2018). Pregnancy diagnosis was assumed to cost NZ $\$ 2.50 /$ cow and treatment (including insemination) was assumed to cost NZ $\$ 65.00$, based on expert veterinary opinion.

Feed Costs. We assumed that all cows that were pregnant at mating end date remained in the herd, calved in the following season and completed a lactation. Conception date was strongly correlated with calving date in the following season in a previous study of cows that were treated with a progesteronebased synchrony program for failure to be detected in estrus (McDougall and Compton, 2006). To calculate feed costs in the following season, we estimated the lactation length and multiplied it by the estimated daily marginal cost of feeding a lactating cow versus a nonlactating cow. To calculate lactation lengths, we assumed that the maximum possible lactation length was $300 \mathrm{~d}$ and the expected lactation length was 300 $\mathrm{d}$ minus the estimated MSD-conception interval (de- 
scribed in the Materials and Methods under "Outcome Assumptions"). The daily marginal cost of feeding a lactating cow versus a nonlactating pregnant cow was calculated by multiplying the extra feed offered in kilograms of DM per day by the feed cost $(\$ / \mathrm{kg}$ of $\mathrm{DM})$. We assumed that lactating cows were offered an extra 7 $\mathrm{kg}$ of DM daily, at a cost of $\mathrm{NZ} \$ 0.30 / \mathrm{kg}$ of DM.

Cow Value. Cows that were pregnant by mating end date were assigned the market value of a pregnant cow of NZ\$1,529.00 (Inland Revenue, 2018). Nonpregnant cows were assigned their slaughter value, calculated from the product of live weight, dressing-out percentage, and market carcass value $(\mathrm{NZ} \$ / \mathrm{kg})$. The slaughter value of a nonpregnant cow was calculated as $\mathrm{NZ} \$ 302.38$, based on the estimated $453 \mathrm{~kg}$ mean live weight of a New Zealand crossbred dairy cow (DairyNZ and Livestock Improvement Corporation, 2018), a dressing-out percentage of $44.5 \%$ (DairyNZ, 2013), and a carcass value of NZ $\$ 3.50 / \mathrm{kg}$ (Interest.co.nz, 2019).
Milk Value. To calculate the value of milk produced in the following season, we multiplied the lactation length (as calculated for feed costs) by the value of one cow-day of milk production, which was the product of mean daily milk yield and the farmgate milk price. Mean daily milk yield was calculated by dividing the 2018 mean national whole-season milk yield ( $\mathrm{kg}$ of milk solids/cow) by the estimated 2018 New Zealand mean lactation length (d), resulting in a value of $1.321 \mathrm{~kg}$ of milk solids/cow per d (DairyNZ and Livestock Improvement Corporation, 2018). The 2008-2018 decadeaverage farmgate milk price of NZ $\$ 6.26 / \mathrm{kg}$ of milk solids was applied (DairyNZ and Livestock Improvement Corporation, 2018).

Calf Value. Calves were assigned a value at $4 \mathrm{~d}$ of age. The AI-bred heifer calves were worth NZ $\$ 400.00$ and all other calves ("bobby calves") were worth NZ\$35.00. 